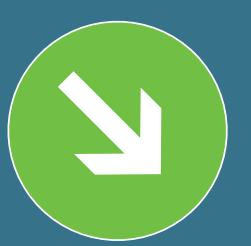

Ключевые слова: смазочно-охлаждающие жидкости (СОЖ), водосмешиваемые СОЖ, щелочность, кислотное разложение, соли жесткости

\section{ЛАБОРАТОРНЫЙ АНАЛИЗ} СМАЗОЧНО-ОХЛАЖДАЮЩИХ ЖИДКОСТЕЙ

\author{
ЧАСТЬ $2^{*}$
}

\section{Александр КЛЕПИКОВ, Константин СМИРНОВ, Сергей СМИРНОВ}

\section{Представлен обзор наиболее важных тестов и методов лабораторного} анализа сложных и многокомпонентных смазочных материалов, к которым относятся водосмешиваемые СОЖ.

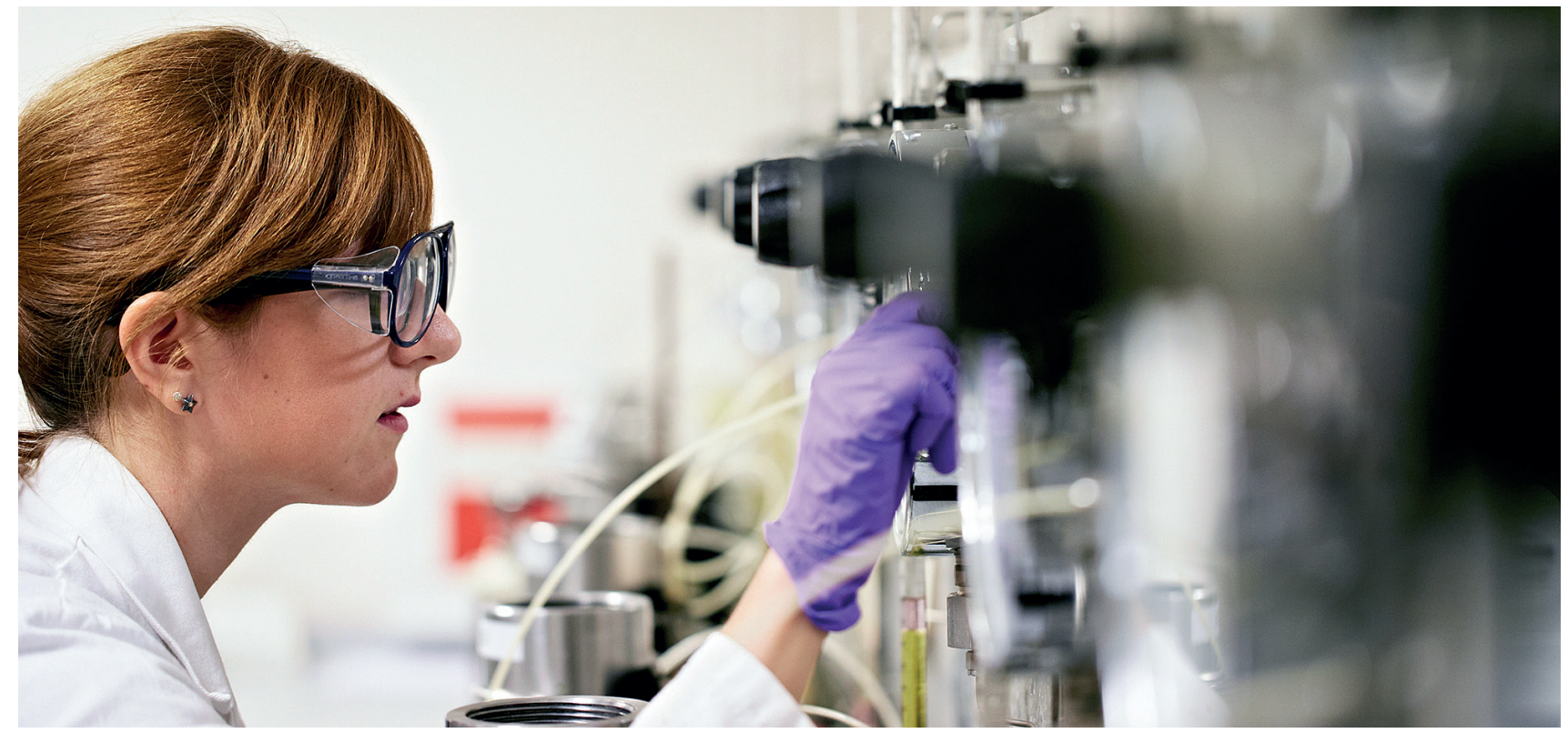

Продолжая статью, опубликованную в предыдущем номере журнала, переместимся в цех к заказчику, где СОЖ, созданная производителем, работает уже в реальных условиях, а затем вернемся снова в лабораторию - сцелью разобраться с необходимым и достаточным набором тестов, результаты которых отвечают на неразрешимые для мобильных цеховых приборов вопросы.

Напомним, что мы рассматриваем лабораторный анализ только водосмешиваемых СОЖ. Краткий обзор методов анализа масляных рабочих жидкостей и ограничений в реализации этого процесса

\footnotetext{
* Начало см. в «СТАНКОИНСТРУМЕНТ», 2020, № 3.
}

был приведен в статье «Мониторинг и сервис смазочно-охлаждающих жидкостей»"*

Начнем, как ни странно, с концентрации эмульсии/раствора. Казалось бы, портативные рефрактометры, как «ручные», так и электронные, давно вошли в обиход подавляющего большинства предприятий. Метод и процесс измерения просты и понятны, проводить измерения может любой сотрудник цеха. Зачем измерять концентрацию еще и в лаборатории? На самом деле не все так просто. Дело в том, что смазочно-охлаждающая жидкость может состоять из десятков ингредиентов, каждый из которых

** См. «СТАНКОИНСТРУМЕНТ», 2020, № 1. 
выполняет определенную функцию. Содержание некоторых из них может увеличиваться в процессе работы (масло, неионогенные ПАВ), тогда как другие вещества будут истощаться (анионные ПАВ, противозадирные присадки). Рефрактометр не способен отразить все эти изменения. Этот прибор хорош для свежеприготовленных эмульсий или растворов, но его точность уменьшается по мере старения рабочих жидкостей и накопления ими загрязнений.

Как правило, в таких случаях мы видим в окуляре или на цифровом дисплее бо́льшие значения, чем есть на самом деле. Хорошая новость состоит в том, что ситуация с истощением компонентов более или менее выравнивается доливом в систему слабоконцентрированной эмульсии в качестве компенсации расхода жидкости на испарение и унос со стружкой. Это еще один аргумент в пользу корректного пополнения системы. Никогда не доливайте в систему просто воду, если хотите получить максимальный срок службы СОЖ без потери технологических и эксплуатационных характеристик.

Постороннее масло, неизбежно попадающее в рабочую жидкость, заслуживает упоминания и в этой статье. Проблема в том, что рефрактометр никак не разделяет и не идентифицирует масло из концентрата и любое другое масло, попавшее извне и эмульгированное жидкостью. В результате, показания прибора искажаются, то есть мы не видим реальной концентрации сбалансированного многокомпонентного продукта. Более того, граница сред при измерении ручным рефрактометром в случаях значительного загрязнения визуально размывается настолько, что говорить о сколько-нибудь точном результате не представляется возможным.

Интересно отметить, что на некоторых предприятиях постороннего масла в СОЖ оказывалось больше, чем концентрата. Что делать в такой ситуации? Конечно же устранять причины попадания подобных загрязнений: подобрать более качественное - с лучшей адгезионной способностью - масло для направляющих скольжения, устранить утечки из гидравлической системы станка и системы привода, установить скиммеры для сбора масла с поверхности до того, как оно эмульгируется и т.д. Однако так мы можем минимизировать проблему, но не устранить ее полностью.

Как сказано выше, какое-то количество масла неизбежно будет поступать в систему. В этом масле нет маслорастворимых компонентов из концентрата, подобранных с учетом всех необходимых функций, которые должна реализовывать жидкость в зоне резания. Это масло выполняло другую работу и было создано специально для этого. Так как же получить реальные значения концентрации при загрязнении посторонним маслом? Комплексно. Необходимо провести еще несколько тестов, а затем сопоставить все результаты и вычислить реальный показатель.
На помощь нам придут измерение щелочности титрованием и тест на кислотное разложение.

\section{ИЗМЕРЕНИЕ ЩЕЛОЧНОСТИ ТИТРОВАНИЕМ}

Измерение щелочности титрованием позволяет нам отследить изменения в этом показателе по сравнению со свежей эмульсией (рис. 1). Щелочность СОЖ снижается в процессе работы вследствие расходования компонентов щелочного буфера на нейтрализацию кислых продуктов жизнедеятельности бактерий. Этот тест имеет самостоятельную ценность, позволяя нам оценить состояние щелочного буфера - важнейшего показателя «здоровья» водосмешиваемой СОЖ.

В этом вопросе $\mathrm{pH}$-метр не дает полной картины, поскольку его показания отражают уже следствие истощения компонентов буфера. При загрязнении рабочей жидкости посторонним маслом щелочность, напротив, растет. При этом для каждого продукта существует свой коэффициент пересчета полученного значения щелочности в концентрацию, полученный опытным путем в лаборатории производителя. К сожалению, этот тест нельзя использовать как самодостаточный для определения концентрации, поскольку щелочность может изменяться не только под влиянием бактерий, как описано выше, но и по мере накопления карбонатов и гидрокарбонатов, поступающих в систему с водой при пополнении. В этом случае показатель растет. В рамках нашей статьи не будем углубляться в различия методов измерения щелочности, применяемых реагентов и терминологий, нам важно в общих чертах понять, как этот инструмент работает.

\section{ТЕСТ НА КИСЛОТНОЕ РАЗЛОЖЕНИЕ}

Суть и выполнение теста на кислотное разложение (в других источниках - тест на разделение кислотой) предельно просты. Он основан на способности сильных кислот взаимодействовать с эмульгаторами, делая их неспособными поддерживать капли масла во взве-

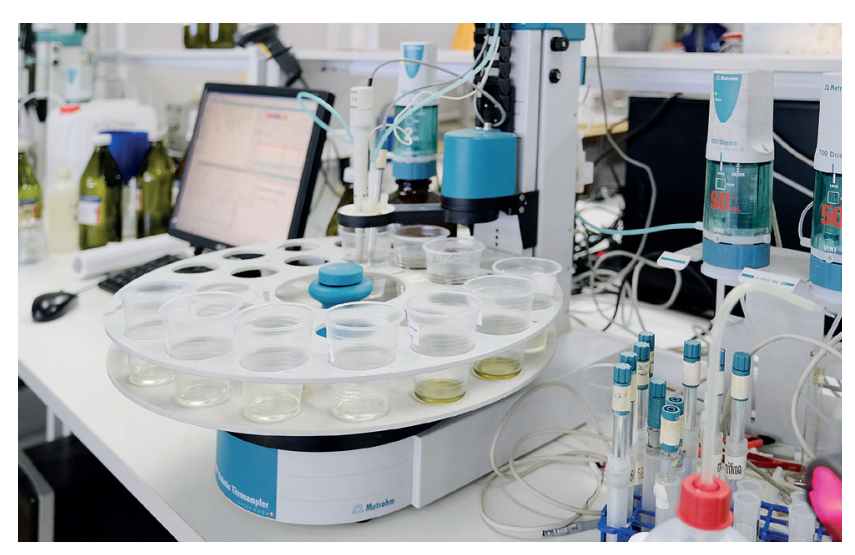

Puс. 1. Процесс титрования 


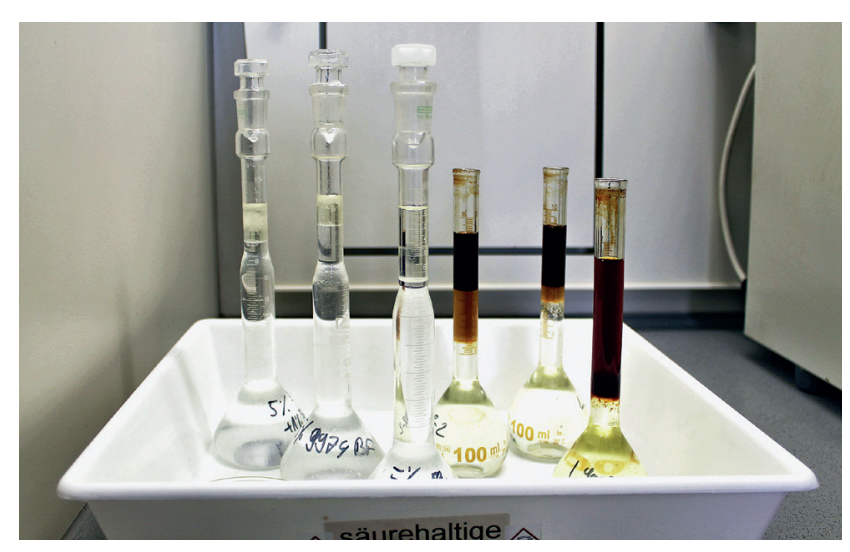

Puc. 2. Тест на разделение кислотой

шенном состоянии в воде, что приводит к разделению эмульсии на водную и масляную фазы. В образец добавляется определенный объем кислоты, после чего емкость помещается в сушильный шкаф и выдерживается при повышенной температуре в течение заданного периода времени (рис. 2). Далее определяется объем верхнего слоя отделившегося масла.

Полученное значение нельзя использовать в чистом виде ни для получения информации о концентрации, ни для выяснения объема постороннего масла в жидкости. В первом случае свой вклад внесет постороннее масло, во втором - масло из концентрата. Однако в составе описанного выше комплекса этот тест хорошо работает.

Подытожим: для относительно точного определения концентрации в случаях загрязнения СОЖ посторонним маслом требуется комплексный подход. Выше мы описали три необходимых и достаточных теста, которые дают ответ на этот вопрос только совместно. Измерение концентрации лабораторным стационарным рефрактометром также входит в этот перечень и предоставляет более точные результаты по сравнению с мобильным цеховым прибором.

\section{СОДЕРЖАНИЕ СОЛЕЙ}

Далее нам необходимо получить данные о содержании солей жесткости в работающей жидкости. Подробнее об их влиянии на саму жидкость и роли в процессе электрохимической коррозии рассказано в статье «Вода как основной компонент эмульсии смазочно-охлаждающей жидкости (СОЖ)»***. Знание о содержании солей жесткости поможет ориентировочно спрогнозировать остаточный ресурс СОЖ или понять причины вдруг появившихся отложений в рабочей зоне станка, сгустков в жидкости или, чего доброго, разделения эмульсии на масляную и водную фазы. Отметим, что оценка остаточного ресурса также требует комплексного подхода.

\footnotetext{
*** См.: «СТАНКОИНСТРУМЕНТ», 2019, № 2.
}

Кроме того, эти измерения имеют ценность в рамках такой задачи, только если проводятся регулярно и у нас есть картина динамики накопления ионов кальция и магния в жидкости. Точные значения по содержанию этих элементов может дать элементный анализ на атомно-эмиссионном спектрометре (рис. 3) с возможностью программного пересчета содержания кальция и магния как элементов в содержание солей жесткости в одном из применимых для наших задач эквиваленте, в данном случае в эквиваленте $\mathrm{CaCO}_{3}$.

Напомним, что тест-полоски для измерения этого параметра хороши как мобильное, недорогое и быстрое решение только до определенных пределов. Эти пределы зависят от производителя полосок, но, как правило, не превышают 350-400 ppm в эквиваленте $\mathrm{CaCO}_{3}$. Как мы писали ранее, в нашей практике есть случаи, когда содержание солей жесткости через полгода работы жидкости составляло 1000 и более ppm $\mathrm{CaCO}_{3}$.

\section{СУЛЬФАТЫ И ХЛОРИДЫ}

Кроме солей жесткости, нас еще интересуют соли серной кислоты (сульфаты) и соли соляной кислоты (хлориды). Интерес этот не праздный, и вот почему. Сульфаты, помимо того, что являются электролитами, включаются в метаболический цикл сульфатредуцирующих бактерий с образованием сульфидов и сероводорода. Для справки: сульфатредуцирующие бактерии в результате своей жизнедеятельности образуют сероводород и сульфид-ионы. Присутствие в коррозионной среде сульфидов и сероводорода ускоряет процесс коррозии путем образования на поверхности металла налета сульфида железа, который облегчает протекание реакции катодной деполяризации. Этот вид бактерий определяется по характерным включениям черного цвета в самой жидкости и на поверхностях оборудования.

Хлориды, как и любые соли, также являются электролитами, однако этим их вредное влияние не ограничивается. Помимо разрушительного влияния на пассивирующую оксидную пленку металла, ионы хлора способствуют росту числа микроанодов

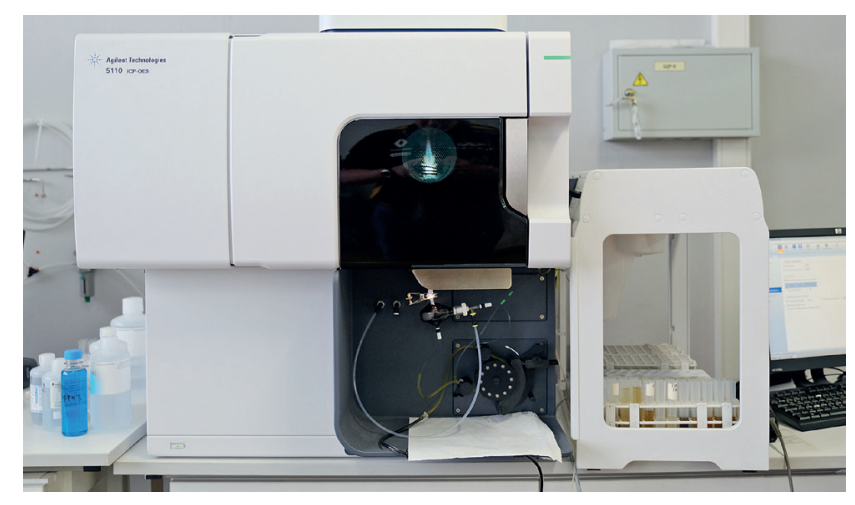

Puc. 3. Атомно-эмиссионный спектрометр 
на поверхности металла, расширяя таким образом область поражения коррозией.

Содержание хлоридов и сульфатов определяется с помощью ионной хроматографии (рис. 4), элементный анализ для этих целей не годится.

\section{ДОПОЛНИТЕЛЬНЫЕ ТЕСТЫ}

Выше мы рассмотрели тесты, входящие в стандартный набор анализа водосмешиваемых СОЖ, который проводится в независимой лаборатории МИЦ ГСМ. В зависимости от стоящей перед заказчиком задачи может потребоваться проведение дополнительных тестов, например:

1. тест на коррозионную активность на чугунной стружке (рис. 5). Он может быть полезным как при выборе СОЖ для операций, где применяется эмульсия или раствор в низкой концентрации, так и при уточнении причины коррозии оборудования и продукции заказчика;

2. щелочность титрованием, когда титрование проводится до нескольких разных значений $\mathrm{pH}$. Это позволяет точнее оценить ситуацию с микроорганизмами и с «запасом прочности» жидкости в отношении нейтрализации кислых продуктов жизнедеятельности бактерий;

3. определение общего количества бактерий и грибков. Для теста также используются дипслайды, однако в лаборатории есть возможность ускорить процесс инкубирования, обеспечив определенные температурные условия;

4. расширенный элементный анализ, позволяющий увидеть посторонние примеси в работающей жидкости.

Все перечисленные тесты также можно провести в МИЦ ГСМ.

\section{ЗАКЛЮЧЕНИЕ}

Ниже представлен список основных и дополнительных лабораторных тестов для общего обзора.

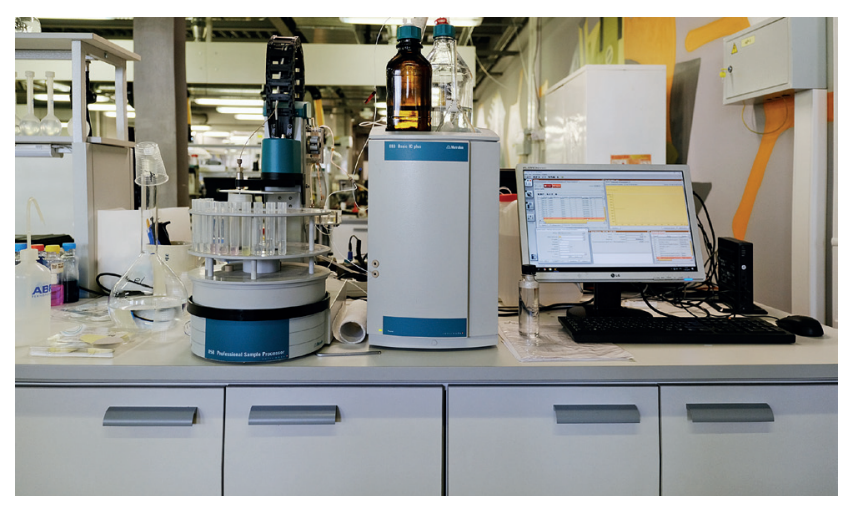

Puc. 4. Ионный хроматограф

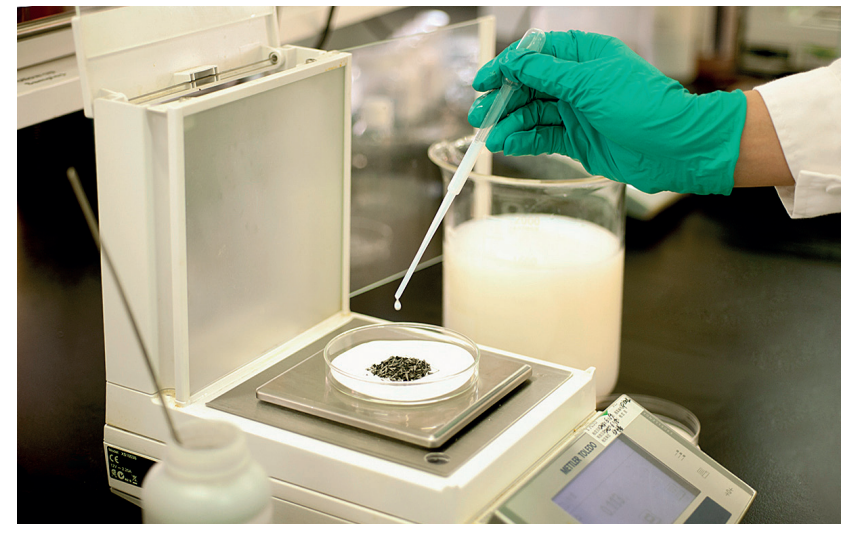

Puc. 5. Тест на чугунной стружке

$\rightarrow$ Основные:

$\checkmark \mathrm{pH}$;

$\checkmark$ удельная электропроводность;

$\checkmark$ щелочность титрованием;

$\checkmark$ концентрация рефрактометром;

$\checkmark$ концентрация щелочным титрованием;

$\checkmark$ концентрация кислотным разложением;

$\checkmark$ содержание постороннего масла;

$\checkmark$ кальций;

$\checkmark$ магний;

$\checkmark$ общая жесткость;

$\checkmark$ сульфаты;

$\checkmark$ хлориды.

$\rightarrow$ Дополнительные:

$\checkmark$ тест на чугунной стружке;

$\checkmark$ щелочность титрованием до разных значений $\mathrm{pH}$;

$\checkmark$ определение общего количества бактерий и грибков;

$\checkmark$ расширенный элементный анализ.

Итак, мы вкратце рассмотрели некоторые наиболее важные тесты и методы лабораторного анализа таких сложных и многокомпонентных смазочных материалов, как водосмешиваемые СОЖ. Безусловно, есть и другие, но, как мы считаем, процесс мониторинга должен быть настолько прост, насколько это позволяет внедрить его как регулярный инструмент сокращения производственных затрат и снижения рисков внеплановых простоев.

\section{КЛЕПИКОВ Александр Михайлович -}

технический консультант по маслам для промышленных предприятий компании Castrol Poсcия

\section{СМИРнОВ Константин Юрьевич - управляющий МИЦ ГСМ}

СмиРнов Сергей Григорьевич руководитель лаборатории МИЦ ГСМ Москва 